NASA/TM-2015-218735

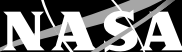

Applications of Nano-Satellites and Cube-Satellites in Microwave and RF Domain

Rainee N. Simons

Glenn Research Center, Cleveland, Ohio

Kavita Goverdhanam

U.S. Army CERDEC, Aberdeen Proving Ground, Maryland 


\section{NASA STI Program . . . in Profile}

Since its founding, NASA has been dedicated to the advancement of aeronautics and space science. The NASA Scientific and Technical Information (STI) Program plays a key part in helping NASA maintain this important role.

The NASA STI Program operates under the auspices of the Agency Chief Information Officer. It collects, organizes, provides for archiving, and disseminates NASA's STI. The NASA STI Program provides access to the NASA Technical Report Server-Registered (NTRS Reg) and NASA Technical Report ServerPublic (NTRS) thus providing one of the largest collections of aeronautical and space science STI in the world. Results are published in both non-NASA channels and by NASA in the NASA STI Report Series, which includes the following report types:

- TECHNICAL PUBLICATION. Reports of completed research or a major significant phase of research that present the results of NASA programs and include extensive data or theoretical analysis. Includes compilations of significant scientific and technical data and information deemed to be of continuing reference value. NASA counter-part of peer-reviewed formal professional papers, but has less stringent limitations on manuscript length and extent of graphic presentations.

- TECHNICAL MEMORANDUM. Scientific and technical findings that are preliminary or of specialized interest, e.g., "quick-release" reports, working papers, and bibliographies that contain minimal annotation. Does not contain extensive analysis.
- CONTRACTOR REPORT. Scientific and technical findings by NASA-sponsored contractors and grantees.

- CONFERENCE PUBLICATION. Collected papers from scientific and technical conferences, symposia, seminars, or other meetings sponsored or co-sponsored by NASA.

- SPECIAL PUBLICATION. Scientific, technical, or historical information from NASA programs, projects, and missions, often concerned with subjects having substantial public interest.

- TECHNICAL TRANSLATION. Englishlanguage translations of foreign scientific and technical material pertinent to NASA's mission.

For more information about the NASA STI program, see the following:

- Access the NASA STI program home page at http://www.sti.nasa.gov

- E-mail your question to help@sti.nasa.gov

- $\quad$ Fax your question to the NASA STI Information Desk at 757-864-6500

- Telephone the NASA STI Information Desk at 757-864-9658

- Write to:

NASA STI Program

Mail Stop 148

NASA Langley Research Center Hampton, VA 23681-2199 
NASA/TM-2015-218735

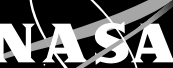

Applications of Nano-Satellites and Cube-Satellites in Microwave and RF Domain

Rainee N. Simons

Glenn Research Center, Cleveland, Ohio

Kavita Goverdhanam

U.S. Army CERDEC, Aberdeen Proving Ground, Maryland

Prepared for the

2015 International Microwave Symposium

sponsored by the Institute of Electrical and Electronics Engineers

Phoenix, Arizona, May 17-22, 2015

National Aeronautics and

Space Administration

Glenn Research Center

Cleveland, Ohio 44135 


\section{Supplementary Notes}

The figures are archived under E-19065.

This report contains preliminary findings, subject to revision as analysis proceeds.

Level of Review: This material has been technically reviewed by technical management.

Available from

NASA STI Program

Mail Stop 148

NASA Langley Research Center

Hampton, VA 23681-2199
National Technical Information Service 5285 Port Royal Road Springfield, VA 22161 703-605-6000

This report is available in electronic form at http://www.sti.nasa.gov/ and http://ntrs.nasa.gov/ 


\title{
Applications of Nano-Satellites and Cube-Satellites in Microwave and RF Domain
}

\author{
Rainee N. Simons \\ National Aeronautics and Space Administration \\ Glenn Research Center \\ Cleveland, Ohio 44135 \\ Kavita Goverdhanam \\ U.S. Army CERDEC \\ Aberdeen Proving Ground, Maryland 21005
}

\begin{abstract}
This paper presents an overview of microwave technologies for Small Satellites including NanoSats and CubeSats. In addition, examples of space communication technology demonstration projects using CubeSats are presented. Furthermore, examples of miniature instruments for Earth science measurements are discussed.
\end{abstract}

\subsection{Introduction}

The history of modern day satellite communications can be traced back to the development of small satellites in the 1960s, with the goal of providing over-the-horizon long-distance telephone service. Explorer-I was the first American satellite that was successfully launched into space on January 31, 1958. The satellite weighed less than $14 \mathrm{~kg}$, of which, $8.4 \mathrm{~kg}$ was instrumentation to detect cosmic rays and micrometeorite impact, and sensors for temperature measurement. The Explorer-I was the first of a series of satellites of that era. The size and mass of these satellites were primarily limited by the capabilities of the launch vehicles of that period. As the launch vehicle capabilities advanced, so did the mass and data throughput of the satellites, which are currently on the order of several $1000 \mathrm{~kg}$ and over $100 \mathrm{Gbps}$. Over the past half a century, the improvements in spacecraft technology have been primarily in the areas of microelectronics for on-board processing, high frequency electron devices, and integrated circuits for communications and navigation, solar cells and batteries for on-board power generation and storage, thruster technologies for propulsion and orbit determination, micromechanical systems (MEMS) and optoelectronic/optical devices for sensors and instruments, etc. Hence, the term small satellite is not revolutionary but merely indicates the progression in technological innovations that has taken place, which has enabled satellite manufacturers to package a wide range of functionality into a small volume at an affordable cost and shorter development time. The efficiencies gained have enabled satellite developers to place useful payloads into small satellites without degrading performance and capability, which was previously possible with only very large satellites.
To cater to a diverse range of missions, the small satellites community has adopted granularity in the overall mass as a basis for defining the mission class. Table I presents these definitions. Among these, the Nanosat has drawn tremendous interest in recent years, because it enables easy and cost effective options, even for small companies and universities, to provide hand-on experience in building a spacecraft and later deploying it in space. The deployment is by sharing the ride to space as a secondary payload, by using the available excess margin, after the integration of the primary payload on to a launch vehicle. Thus the major benefit is the significantly lower cost to develop and deploy a Nanosat compared to a conventional large satellite.

To facilitate the above goals of providing low cost access to satellites, the community has further adopted a standard, which is dubbed as CubeSat. Prof. R.J. Twiggs at the Stanford University pioneered the development of CubeSats (Ref. 1). A CubeSat measures $10 \mathrm{~cm}$ on a side, weighs about a $\mathrm{kg}$, and is assembled using commercial-off-the-shelf (COTS) components. This form factor is defined as " $1 \mathrm{U}$ " unit. A single CubeSat could either serve as a standalone satellite with limited functionality or serve as a building block for a larger Nanosat or a Microsat. For example, a "3U" Nanosat will consist of three CubeSats. Thus, the major advantage of this standardization is that launch vehicle manufacturers, regardless of who built the CubeSats, can adopt a common deployment system. Prof. J. Puig-Suari at the California Polytechnic State University developed such a standard deployment system. This system is known as the Poly Picosatellite Orbital Deployer (P-POD) (Ref. 1). This deployment system can accommodate multiple Nanosats with a range of form factors, which allows spreading the launch cost across several customers, resulting in lower launch cost per customer. Applications of Nanosats include, communications, remote sensing, scientific research, high-resolution still imagery, maritime applications such as ship tracking, formation flying to create large synthetic aperture for imaging radar, etc. 
TABLE I.-SMALL SATELLITE NOMENCLATURE

\begin{tabular}{|l|l|}
\hline \multicolumn{1}{|c|}{ Generic name } & \multicolumn{1}{c|}{ Launch weight $^{\mathrm{a}}$} \\
\hline Smallsat & 100 to $500 \mathrm{~kg}(220$ to $1100 \mathrm{lb})$ \\
\hline Microsat & 10 to $100 \mathrm{~kg}(22$ to $220 \mathrm{lb})$ \\
\hline Nanosat & 1 to $10 \mathrm{~kg}(2.2$ to $22 \mathrm{lb})$ \\
\hline Picosat & 0.1 to $1 \mathrm{~kg}(0.22$ to $2.2 \mathrm{lb})$ \\
\hline
\end{tabular}

${ }^{a}$ Wet mass with fuel at launch

\subsection{Challenges Facing the Small Satellite Industry}

The first and foremost challenge for the small satellites is the radio spectrum. The uplink and downlink frequencies for CubeSats are typically in the UHF band (435 to $438 \mathrm{MHz}$ ), which are regulated by the International Amateur Radio Union (IARU). At UHF the available bandwidths are very small and so are the achievable data rates. Hence, there is a push to migrate into the higher X-band and Ka-band frequencies, were the available bandwidths are larger. However, this requires special license to deploy and operate.

The second challenge for small satellites is the sustainability of the business in the case of small start-up companies. An area that has drawn a lot of interest in using small satellites is remote sensing of the Earth from space. These service providers propose using a constellation of small satellites that are capable of delivering global high-resolution scientific grade Earth multispectral imagery on a daily basis. Applications may include both commercial and military. Potential applications may include agriculture yield, oil and natural gas exploration and production, deforestation, mapping and geospatial services, tracking of ships in seas, emergency response, national security, mobile device support, etc.

The next challenge for small satellites is the cleanup and removal of space debris. Thus, small satellite manufactures will need to develop an innovative mechanism to deorbit at the completion of their mission.

Finally an additional challenge for small satellites, is finding the appropriate launch opportunity with affordable cost. This issue has been partly addressed by sharing the ride as a secondary payload, on a launch vehicle equipped with a P-POD system.

\subsection{CubeSat Architecture}

The CubeSat architecture is modular and each subsystem resides on a separate printed circuit board. The subsystems include the communications subsystem (CS), the on-board controller (OC), the attitude determination and control (ADC) subsystem, the electronic power supply (EPS), and the payload. The OC routes the data from the payload to the CS and operates the radio in the CS. In addition, it processes the data from the $\mathrm{ADC}$, controls the EPS, and facilitates communications between the various subsystems through the satellite bus. A simplified block schematic of the CubeSat architecture is presented in Figure 1.

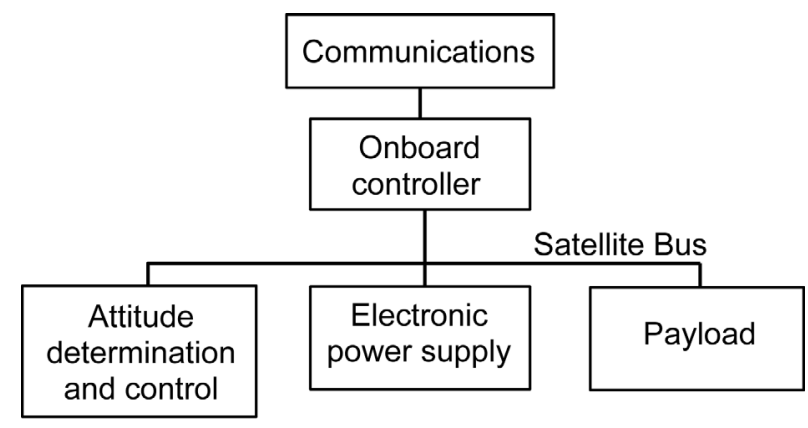

Figure 1.-A simplified block schematic of CubeSat architecture.

\subsection{CUBESAT Communications Subsystem}

The communications subsystem not only supports the transmission of the data from the payload to the ground station but is also responsible for the tracking, telemetry, and command functions. The communications subsystem consists of the radio and the antenna. The radio includes the transceiver, the low noise amplifier (LNA), the high power amplifier (HPA), and the diplexers. A simplified block schematic of the communication subsystem is presented in Figure 2.

\subsection{Antenna}

The CubeSat antenna must have an omnidirectional radiation pattern to communicate with Earth terminals located at any latitude. A second requirement is that the antenna must be capable of being stowed during launch and later deployable onorbit. To meet these requirements a deployable turnstile antenna is recommended. The turnstile antenna consists of four monopole antennas located at the four corners of either the top or bottom panel of the CubeSat and properly phased so as to generate a circularly polarized (CP) omnidirectional radiation pattern.

\subsection{Transceiver}

The transceivers are commercially available from several vendors and operate in a half-duplex mode. They are configured to transmit and receive data at rates ranging from $1.2 \mathrm{kbps}$ up to $9.6 \mathrm{kbps}$ using a variety of modulation schemes including FSK, GMSK, and GFSK, etc. They are also capable of implementing both forward error correction (FEC) and Viterbi coding. The typical operating frequencies have been in the UHF band. However, in some instances, CubSats have operated in the Industrial Scientific and Medical (ISM) band $(2.4 \mathrm{GHz})$ and in the Space Research band (2.2 to $2.29 \mathrm{GHz}$ ). 


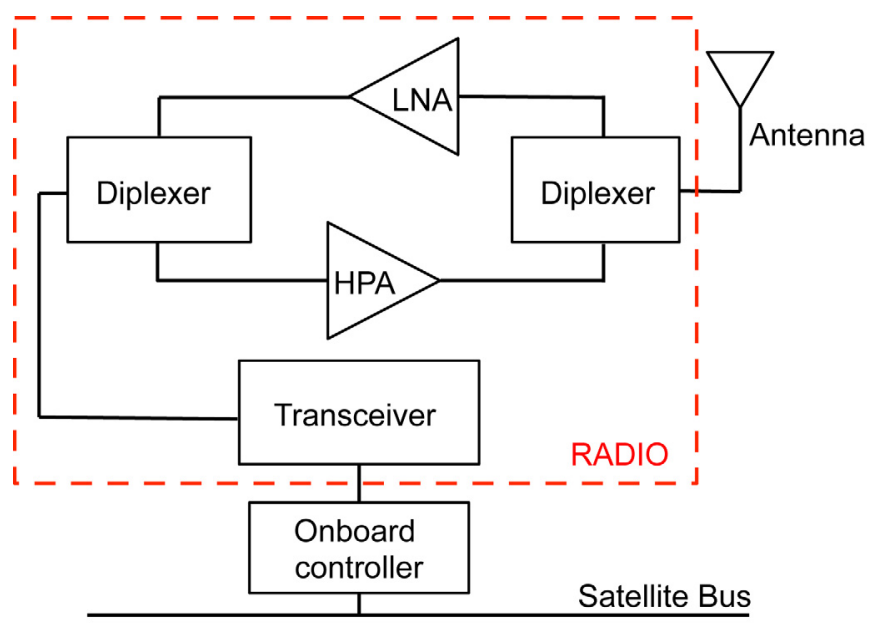

Figure 2.-A simplified block schematic of the communication subsystem.

\subsection{Low Noise Amplifiers (LNA) and High Power Amplifiers (HPA)}

At the operating frequencies indicated above, the noise figure of LNAs is typically on the order of 0.5 to $0.7 \mathrm{~dB}$. The gain is in the range of 15 to $20 \mathrm{~dB}$. The output power of HPAs typically ranges from 0.5 to $2 \mathrm{~W}$, which is adequate to close the link at the above mentioned data rates.

\subsection{Examples of NASA's Small Satellite Communication Technology Missions and Demonstrations}

In the section below, NASA's two CubeSat Technology Demonstration missions, one Smallsat Network mission, three CubeSat flight demonstration missions and three Smallsat Technology Partnership Projects will be briefly described.

\subsection{PhoneSat Missions}

The first PhoneSat housed in a $1 \mathrm{U}$ CubeSat platform and launched into a low Earth orbit (LEO) in April 2013 was to validate the use of smartphone and other commercially available consumer-grade electronics in space (Ref. 2). Subsequently, in November 2013 and April 2014, PhoneSat 2.4 and PhoneSat 2.5 mission were launched. All of the above served as technology demonstrations and risk mitigation precursor missions to the upcoming Edison Demonstration of Smallsat Networks (EDSN) Mission, which is described below. They also provided further confidence in the PhoneSat concept and electronic components by investigating their survivability in space radiation environment.

\subsection{Edison Demonstration of Smallsat Networks (EDSN) Mission}

This mission will launch in early 2015, eight, $1.5 \mathrm{U}$ CubeSats into LEO $(\sim 500 \mathrm{~km})$ (Ref. 3). These satellites based on PhoneSat architecture will have cross-link communications capability and perform a wide range of scientific research. The primary goal of the mission is to demonstrate that a swarm of nanosatellites can be configured to simultaneously gather multipoint science data and downlink the data to a ground site. The cross-link and downlink communications are at UHF and Sband frequencies, respectively.

\subsection{Optical Communications and Sensor Demonstration (OCSD)}

The OCSD mission will consist of two, 1.5U CubeSats in near-circular LEO with an inclination of $34^{\circ}$ (Ref. 4). The first objective of this mission is the demonstration of a space-toground optical communications link at $1064 \mathrm{~nm}$ wavelength. The target data rate achievable with this system is on the order of $5 \mathrm{Mbps}$, which is faster by two orders of magnitude than the current capability at UHF.

The second objective is to demonstrate a small automotive anti-collision radar sensor $(77 \mathrm{GHz})$ repurposed to determine the range between the two CubeSats in close proximity. Recent studies indicate that a laser rangefinder is better suited for this task since it is smaller, lighter, requires less prime power, and has multi-kilometer range. The two CubeSats equipped with this sensor will maneuver to within $200 \mathrm{~m}$ of each other using on-board GPS to determine their relative position and velocity. Proximity operations capability will enable multiple small spacecrafts to operate cooperatively in a science mission, approach another spacecraft for observation/servicing, or fly information to form a synthetic aperture radar (SAR) for Earth surface mapping. The OCSD mission will be launched in 2015.

\subsection{Integrated Solar Array and Reflectarray Antenna (ISARA) for High Bandwidth CubeSat}

The ISARA mission will demonstrate a Ka-band $(26 \mathrm{GHz})$ high gain $(\sim 35 \mathrm{~dB})$ reflector antenna using the back of a $3 \mathrm{U}$ CubeSat's deployable solar array panel as a reflector (Ref. 5). The projected data rates are as high as $100 \mathrm{Mbps}$ from LEO, which are several orders of magnitude higher than the data rates achievable at the UHF band. The above high-bandwidth communications demonstration will enable small satellites to perform radar/radiometry science missions that were previously only possible on large satellites. The projected launch date is late 2015. 


\subsection{CubeSat Proximity Operations Demonstration (CPOD)}

Two 3U CubeSats will be launched in 2015/16 time frames with the objective to demonstrate (Ref. 6): (1) Ability to remain at determined points relative to each other on-orbit. This capability is essential for inspection/servicing of satellites or remote sensing of an asteroid in support of a science mission. (2) Precision circumnavigation using imaging sensor and cold gas propulsion systems. (3) A universal docking mechanism. The ability to circumnavigate and dock is essential for flying information or joining to form a large orbiting structure, such as a mirror for a telescope. During navigation, visual images of each CubeSat will be transmitted via a space-to-ground link to the control center for ensuring proper operations. In addition, GPS information will be exchanged between the two CubsSats via an inter-satellite link.

\subsection{Network and Operation Demonstration Satellite (NODES)}

This mission will build on the successes of the PhoneSat series of missions presented earlier (Ref. 7). In addition, it will exploit the knowledge from the experience gained in the development of hardware and software for the EDSN mission. In this mission, two $1.5 \mathrm{U}$ cubeSats will be launched from the International Space Station (ISS) with the objective to demonstrate software that can perform command and data handling tasks. The mission plans to showcase this capability by relaying ground commands through one CubeSat to the second CubeSat. In addition, science instruments on each CubeSat will measure the space radiation in the proximity of the ISS and relay the information to ground. The deployment is expected to take place in early 2015 .

\subsection{High Rate CubeSat X-band/S-band Communication System}

The goal of this technology demonstration project is to develop a high data rate X-band CubeSat communication system that is compatible with NASA's Near-Earth Network. Preliminary investigations indicate that a communication system operating at a center frequency of $8.38 \mathrm{GHz}$ can be built using commercially available parts (Refs. 8 and 9). The link simulations assume a transmit power of $1 \mathrm{~W}$, transmit waveform to be QPSK with FEC capability, and transmit antenna gain of $0 \mathrm{dBi}$. The target data rate achievable from LEO with this system is on the order of $12.5 \mathrm{Mbps}$ with a ground antenna diameter of $12 \mathrm{~m}$.

\subsection{Development of Novel Integrated Antennas for CubeSats}

CubeSats make use of a wire or tape antenna for communications. The disadvantage of this type of antenna is that they require a deployment mechanism and are also prone to damage, which can lead to mission failure. Hence, the goal of this project is to demonstrate low-profile transparent microstrip antennas that are conformal to the surface of the solar panels of a CubeSat. Initial design studies indicated that a meshed patch antenna on a transparent quartz substrate is an excellent candidate for generating a linearly polarized (LP) antenna pattern at $2.4 \mathrm{GHz}$ (Refs. 9 and 10). Extending this design to a $\mathrm{CP}$ version is also planned. The pioneering development of optically transparent microstrip patch antennas on flexible and on glass substrates is reported in References 11 and 12.

\subsection{Example of NASA's In-Space Validation of CubeSat Based Microwave Small Instruments and Subsystems for Earth Science Measurements}

\subsection{The Microwave Radiometer Technology Acceleration (MiRaTA) CubeSat}

This CubeSat mission will validate the following new subsystem and measurement technologies (Ref. 13): (1) Ultra compact and low-power radiometers operating at 52 to $58 \mathrm{GHz}, 175$ to $191 \mathrm{GHz}$, and 206 to $208 \mathrm{GHz}$. (2) GPS receiver and antenna array for tropospheric radio occultation sounding. (3) Radiometer calibration using concurrent GPS radio occultation measurements. The above set of demonstrations will significantly enhance the capabilities of future weather and climate sensing microwave instruments.

\subsection{Summary of European Small Satellite Communication Technology Demonstrations}

The CubeSat community in Europe has made tremendous strides in the development of inflatable and printed antennas, Global Navigation Satellite System (GNSS) receivers, transponders, software defined radios, and networked ground receiving stations, etc., for small satellites. References 14 and 15 are good sources of information on these developments. 


\subsection{Conclusion}

Small Satellites such as CubeSats, NanoSats and MicroSats is an emerging disruptive technology area with a broad range/scope of applications in the RF and Communications fields. While the scope of applications is still being studied, it is clear that this technology offers tremendous benefits in many space applications. These benefits can be further enhanced through the use of $3 \mathrm{D}$ printing technology, which has the potential to significantly reduce the manufacturing cost, total time for the design cycle, and material waste.

\section{References}

1. H. Heidt, J. Puig-Suari, A.S. Moore, S. Nakasuka, and R.J. Twiggs, 2000, "CubeSat: A New Generation of Picosatellite for Education and Industry Low-Cost Space Experimentation," Proceedings of the $14^{\text {th }}$ Annual AIAA/USU Conference on Small Satellites, Lessons Learned-In Success and Failure, SSC00-V-5. http://digitalcommons.usu.edu/smallsat/2000/All2000/32/

2. The PhoneSat Series of Smartphone Nanosatellites, NASAfacts, http://www.nasa.gov/sites/default/files/files/ PhoneSatFactSheet-27May14.pdf

3. Edison Demonstration of Smallsat Networks (EDSN) Mission, NASAfacts, http://www.nasa.gov/sites/default/ files/files/EDSN_Fact_Sheet-15Oct14.pdf

4. S.W. Janson and R.P. Welle, 2014, "The NASA Optical Communication and Sensor Demonstration Program: An Update," Proceedings of the 28th Annual AIAA/USU Conference on Small Satellites, Next on the Pad, SSC14-VI-1. http://digitalcommons.usu.edu/smallsat/2014/NextPad/1/

5. R. Hodges, B. Shah, D. Muthulingham, and T. Freeman, 2013, "ISARA-Integrated Solar Array and Reflectarray Mission Overview," Proceedings of the 27 th Annual AIAA/USU Conference on Small Satellites, PreConference: CubeSat Developer's Workshop. http://digitalcommons.usu.edu/smallsat/2013/all2013/12/

6. S. MacGillivray, "Proximity Operations Nano-Satellite Flight Demonstration (PONSFD) Overview," $10^{\text {th }}$ Annual CubeSat Developers Workshop, Cal Poly, San Luis Obispo, CA, April 24-26, 2013. http://www.cubesat.org/ index.php/workshops/past-workshops/1282013summerworkshoppresentations
7. Network \& Operation Demonstration Satellite (NODES), NASAfacts, http://www.nasa.gov/sites/default/files/files/ Nodes-Fact_Sheet-23July14(1).pdf

8. S. Palo, D. O'Connor, E. DeVito, R. Kohnert, G. Crum, and S. Altunc, 2014, "Expanding CubeSat Capabilities with a Low Cost Transceiver," Proceedings of the $28^{\text {th }}$ Annual AIAA/USU Conference on Small Satellites, Advanced Technologies-Communications, SSC14-IX-1. http://digitalcommons.usu.edu/smallsat/2014/AdvTechC omm/1/

9. Smallsat Technology Partnerships, NASAfacts, http:/www.nasa.gov/sites/default/files/files/SSTP_Partn erships_Program_Fact_Sheet.pdf

10. R. Montano, N. Neveu, S. Palacio, E. Martinez, D.R. Jackson, J. Chen, P.W. Fink, and R.S. Provence, 2014, "Development of Low-Profile Antennas for CubeSats," Proceedings of the $28^{\text {th }}$ Annual AIAA/USU Conference on Small Satellites, Advanced Technologies-Communications, SSC14-IX-7. http://digitalcommons.usu.edu/smallsat/2014/ AdvTechComm/7/

11. R.N. Simons and R.Q. Lee, "Feasibility Study of Optically Transparent Microstrip Patch Antenna," IEEE Antennas and Propagation Society Inter Symp Digest, vol. 4, pp. 2100-2103, Montreal, Canada, July 13-18, 1997.

12. R.N. Simons and R.Q. Lee, U.S. Patent \#5,872,542, Optically Transparent Microstrip Patch \& Slot Antennas, Feb 16, 1999.

13. The Microwave Radiometer Technology Acceleration (MiRaTA) Cubesat, W. Blackwell, MIT Lincoln Laboratory. http://esto.nasa.gov/files/solicitations/ INVEST_12/ROSES2012_InVEST_awards.html\#black

14. $5^{\text {th }}$ European CubeSat Symposium, Book of Abstracts, Ecole Royale Militaire, Brussels, June 3-5, 2013.

15. $6^{\text {th }}$ European CubeSat Symposium, Book of Abstracts, Estavayer-le-Lac, Switzerland, Oct 14-16, 2014. 


